\title{
Digital. Asset. Management. So what?
}

\begin{abstract}
Niclas Ljungberg
is a thought leader and eminent practitioner in the use and renewal of intangible assets. He is Co-Chairman of the Intellectual Capital Network, a founding member of the brand think-tank the Medinge Group, and a Director of Placebrands. He has extensive cross-cultural experience, currently based in London and prior to that Hong Kong, born in Sweden and has worked and lived in Europe, Asia, and Africa for more than 15 years.
\end{abstract}

Keywords: digital, asset, management, intangible, financial

Abstract Digital asset management, often abbreviated as DAM, is a rapidly emerging field where many different disciplines meet for the delivery, who along with a plethora of buyers with diverse needs are trying to make sense of exactly what DAM means, what it does and why it is good. This paper looks at some of the parts that make up the whole; what it means being "digital"; what an "asset" is; and what "management" may involve.

\section{INTRODUCTION}

Digital asset management. Digital. Asset.

Management. DAM. With the launch of its own journal this seems a good opportunity to take one of those infamous steps back and think a bit about what we actually mean when we use these words.

They may be crystal clear to everyone within a tightly knit DAM community (if indeed there is such a thing), who share a concise and undisputed notion of what DAM denotes. Somehow I doubt it though. Among other things, I chair the Intellectual Capital Network in the UK, and whenever people get together to discuss things like "knowledge", which has been around as a concept for a while and should thus be likely to be defined and agreed, groups can and will spend endless and rather passionate sessions arguing about what "it" is, why it is useful, for whom, and so on.

The purpose of this short piece is not to provide the final analysis or come up with the definitive definition. Rather, it is to remind ourselves that words are complex beings, and concepts conceived from no fewer than three words may, or may not, be easily understood by all, or mean the same thing across different contexts. As digital asset management is an expanding area, we need to exercise care when preaching its virtues to the world, be clear about the underlying principles, and keep asking ourselves those stretching questions.

All we need to do is to ask ourselves the questions any typical ten-year-old would ask before going to school on a rainy morning. What does it all mean? Why do we bother?
For instance, take the plethora of associated acronyms that swamp the field of DAM. To name but a few: BRM, BIM, CMS, CRM, ECM, EMM, ERP, ILM, MAM, MOM, MRM, PDF, SCM, XML. Enough to make any $\mathrm{CEO}, \mathrm{CFO}, \mathrm{CIO}, \mathrm{CMO}$ or CTO scratch their heads in mission critical bewilderment. Although a slight amount of jargon is bound to haunt any field related to technology these days, the important thing is not to hide behind it but to explain in clear and straightforward English (or whatever your local language is) what we are talking about. Sound simple? Try it.

Borrowing freely from the world of biological taxonomists, I have been told there are basically two kinds of people in this world, lumpers and splitters. The lumpers tend to generalize, look at similarities and group things into higher orders; the splitters like to look at specific details and differences to break things down further. It can be an interesting exercise to figure out what kind of person you, and the people with whom you work are.

So what would a splitter say about all this? Let's look at the separate components, and see what some of the dictionaries have to say. Digital. Asset. Management.

\section{DIGITAL}

Digital as a concept is all around us, and these days, so many things seem to be digital just for the sake of the label. It can mean something done with a finger; having digits or displaying numbers rather than scale positions. And, of course, the opposite of analog, as in data that are 
stored or transmitted as a sequence of discrete symbols from a finite set, most commonly using binary data represented using electronic or electromagnetic signals.

Of more relevance is perhaps Nicholas Negroponte in his manifesto "Being Digital", where he spoke about the differences between bits and atoms, ie being digital versus being physical, virtual versus real. ${ }^{1}$ He sketched the brave new world that was coming when many of the old barriers to doing business would be eradicated; traditional diminishing returns to scale would be turned upside down since anything stored digitally can be reused, resold, reconsumed, and transferred around the world as many times as we like without incurring extra costs. But as he noted in Wired, "bits are bits but not all bits are created equal."

\section{ASSET}

An asset is a valuable item that is owned. In accounting terms it can be described as the entries on a balance sheet showing all properties, both tangible and intangible, and claims against others. Intangibles, another evolving and debated field, has so far come to mean property rights and goodwill.

There are rules for what may be determined a financial asset for accounting purposes, and practices will differ slightly eg between the USA and Europe. Increasingly these days all sorts of intangible assets can be validated and capitalized (or are about to be eligible), ie put on the balance sheet with a specific value, such as brands, investments in product development in software, and indeed digital assets.

Broadly speaking, auditors will look at things like whether you can prove future economic benefits and returns; that the asset is identifiable and separable; that the company can prove ownership and legal rights to it. There is also a difference between acquisition and internally generated assets. If you buy another company and therefore actually pay a price for intangible assets, they have a value and can be capitalized (what as is another matter). If it is produced inhouse it becomes more difficult, but any asset should at least have a readily ascertainable market value. I know of one car manufacturer looking to capitalize their product improvement "costs" as investments.

\section{MANAGEMENT}

The final part of the trinity, management what we propose to do with these digital assets - brings to mind issues of control, process, Taylorism, measurement, and Peter Drucker. Management is said to be the act, manner, or practice of managing - handling, supervision, or control; it is also defined as business dealing, negotiation, arrangement.

Not to forget the popular definition of the noun, ie corporate power elites distinguished primarily by their distance from actual productive work and their chronic failure to manage (see also "suit"). Mythically speaking, management is a vast bureaucracy responsible for all the world's minor irritations.

There are a great number of things that can be done to "manage" a digital asset — from it being created; manipulated (understood, catalogued, stored, accessed, distributed, transferred, exchanged, shared); secured (access) and protected (rights); sold; licensed; measured; valued; converted to something physical (and vice versa) and so on.

\section{SO WHAT?}

All of this means there are tools, processes, objects, metadata, and so on to define why these digital assets need managing in the first place, and to distinguish and match overall corporate objectives with business unit tactical objectives. Why? To solve otherwise unsolvable problems? To make more money? To save money? To do something quicker? To make customers happier? To ensure consistency? You tell me. Or rather let your customers tell you.

Now let's try the lumper approach.

When talking about DAM, because of the traditional multimedia nature of these assets we focus mostly on industries such as printing, publishing, design, entertainment, media, or software. These all manage digital assets of some reasonably obvious type in different value chains as part of their core business. More recently, similar digital assets are being managed for the purpose of branding.

There is also an ongoing debate (some may say it is long since settled but I keep reading contradictory articles) about the conceptual or hierarchical relationship between some of those acronyms we touched on earlier, such as document management, content management, 
enterprise content management, and why not knowledge management or e-learning.

One distinction may be whether we are talking about what it is, or what it represents? Or both? Is it digital as actual direct asset (consuming digital content), or the indirect representation of something (information about what can be sold)?

Is it all just about keeping track of text and pretty pictures, whether still or moving? Loosely speaking, aren't all databases concerned with digital asset management? Certainly, it seems a fair definition of what a computerized database is and does. But would that mean that anything done on a computer could be called digital asset management? Quick, name the world's largest DAM product? Windows...

Speaking of tangible assets that become increasingly intangible, how about money these days - aren't all banks, the ultimate asset managers, just more or less digital asset managers? Think abut how much money travels the world every day in electronic foreign exchange systems, not existing one second as physical coins and notes. Tell me these people aren't digital asset managers . . .?

There is a long and winding, and quite interesting, evolutionary road ahead as the DAM community will seek to answer these and many more questions. It is my hope that this new journal will be a central and engaging forum for that debate. Here's to many happy readings.

\section{Reference}

1 Negroponte, N. (1996) Being Digital, Coronet Books, London, UK. 